\title{
Penetration of Different Liquids in Wood-Based Composites: The Effect of Adsorption Energy
}

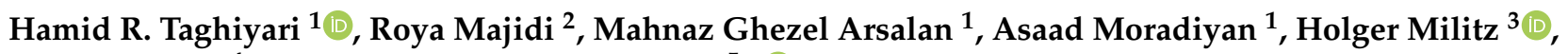 \\ George Ntalos ${ }^{4}$ and Antonios N. Papadopoulos $5, * \mathbb{C}$
}

1 Wood Science and Technology Department, Faculty of Materials Engineering \& New Technologies, Shahid Rajaee Teacher Training University, Tehran 16788-15811, Iran; htaghiyari@sru.ac.ir (H.R.T.); mahnaz_arsalan2@yahoo.com (M.G.A.); pranawood66@gmail.com (A.M.)

2 Department of Physics, Faculty of Sciences, ShahidRajaee Teacher Training University, Tehran 16788-15811, Iran; r.majidi@sru.ac.ir

3 Wood Biology and Wood Products, Georg-August-University Göttingen, 37077 Göttingen, Germany; hmlitz@gwdg.de

4 Department of Forestry, Wood Science and Design, University of Thessaly, GR-431 00 Karditsa, Greece; gnatalos@uth.gr

5 Laboratory of Wood Chemistry and Technology, Department of Forestry and Natural Environment, International Hellenic University, GR-661 00 Drama, Greece

* Correspondence: antpap@for.ihu.gr; Tel.: +30-252-106-0445

Citation: Taghiyari, H.R.; Majidi, R.; Arsalan, M.G.; Moradiyan, A.; Militz, H.; Ntalos, G.; Papadopoulos, A.N. Penetration of Different Liquids in Wood-Based Composites: The Effect of Adsorption Energy. Forests 2021, 12, 63. https://doi.org/10.3390/f12010063

Received: 14 December 2020

Accepted: 4 January 2021

Published: 7 January 2021

Publisher's Note: MDPI stays neutral with regard to jurisdictional clai$\mathrm{ms}$ in published maps and institutional affiliations.

Copyright: $\odot 2021$ by the authors. Licensee MDPI, Basel, Switzerland. This article is an open access article distributed under the terms and conditions of the Creative Commons Attribution (CC BY) license (https:// creativecommons.org/licenses/by/ $4.0 /)$.

\begin{abstract}
The penetration properties of three different liquids on the surface of medium-density fiberboard (MDF) and particleboard panels were studied. Water, as a polar liquid, was compared to two other less polar liquids (namely, ethanol and kerosene) with significantly larger molecules. Measurement of penetration time and wetted area demonstrated significantly higher values for water in comparison with the other two liquids, in both composite types. Calculation of adsorption energies, as well as adsorption distances, of the three liquid molecules on hemicellulose showed higher potentiality of water molecules in forming bonds on hemicellulose. However, comparison of the adsorption energies of cellulose with hemicellulose indicated a higher impact of the formation of bonds between hydroxyl groups in water and cellulose in hindering the penetration of water molecules into the composite textures. It was concluded that the formation of strong and stable bonds between the hydroxyl groups in water and cellulose resulted in a significant increase in penetration time and wetted area.
\end{abstract}

Keywords: adsorption properties; hydroxyl groups; medium-density fiberboard (MDF); particleboard panels; polar molecules

\section{Introduction}

Wood-based composite panels with desirable length and width can satisfy the growing needs in the home and office furniture market; therefore, these panels have become an essential part of household and office lives in many countries [1-9]. However, usually, the wood-based composite panels are susceptible to water and moist conditions, particularly those panels produced with urea-formaldehyde (UF) resin [10-12].

Concerning the description of wetting processes, and the prediction of the wettability of a solid by different liquids, the surface tensions of both the liquid and solid are of importance. All thermodynamic theories concerning the wetting behavior are based on a flat and isotropic (ideal) surface of the solid, which, however, does not exist in practice. For measuring contact angles on real surfaces, it is important to know the various parameters influencing the contact angles of liquid droplets applied onto the surfaces. These parameters depend on the nature and properties of the wetting liquid as well as of the wetted solid surface. This especially is an unalterable presupposition for measuring contact angles on wood, which differs from many other materials in terms of its cellular 
structure. One point to consider is the effect of the roughness of the wood surface, including the influence of the wood moisture content of the samples on the dynamic contact angles and on the surface tensions of solid wood, calculated from these contact angles. Zorll [13] infers that liquids still are able to wet such a rough surface, whereas on an ideal flat surface with no roughness, no proper wetting occurs. Wettability measurements performed by Hse [14] using phenol-formaldehyde resins and pine veneers showed lower static contact angles on the rougher early-wood surfaces than on the smoother latewood surfaces.

As wood is a hygroscopic material, it must be assumed that the moisture content of wood influences the wettability of wood surfaces by liquids. When a droplet of water comes into contact with dry wood, swelling processes of wood take place underneath the droplet and the wood surface structure might change. A low wood moisture content impedes the wettability. A possible reason for this can be the lower number of hydrophilic hydroxy groups of the wood, which act as a sorption place for water molecules [15]. This consideration, however, is only valid for wetting wood with aqueous liquids or alcohols. Severe conditions, e.g., high temperatures during hot pressing in the production of woodbased panels, might cause a decrease of the number of cellulose-based $\mathrm{OH}$-groups with a lower wood moisture content, which causes a thermic deactivation of the wood surface. Upon applying heat energy to the surface, an activation of wood components might occur, causing cleavage of chemical bonds [16].

In this connection, having a better outlook on the penetration patterns of different liquids that may either affect wood or the resin used in the composite would provide both researchers and the industry sector with an in-depth understanding of how the panels may be affected by different liquids. Therefore, the present study was designed to find out how water, as a polar liquid, and two other less polar liquids (namely, ethanol and kerosene) penetrate into and expand throughout the surface of composite panels. Two popular wood-based composites were chosen for this purpose: medium-density fiberboard (MDF) and particleboard panels. Urea-formaldehyde resin was used as a binder in both panels, however, further studies on panels with other binders (like phenol-formaldehyde and melamine-formaldehyde resins) would provide additional useful information for comparison purposes. Moreover, the adsorption energy and adsorption distance of the above mentioned liquids on hemicellulose were also calculated by density functional theory (DFT) to further investigate to what extent theoretical studies comply with experimental tests.

\section{Materials and Methods}

\subsection{Specimen Preparation}

Three MDF panels and three particleboard panels from industrial production were selected. MDF panels were produced by Khazar Company, Amol, Iran, with a density of $750 \mathrm{~kg} \cdot \mathrm{m}^{-3}$. Urea-formaldehyde resin content was $12 \%$ based on the dry weight of wood fibers, with an addition of $0.5 \%$ liquid paraffin. Fibers were comprised of poplar (Populus nigra) (50-60\%), a mixture of industrial wood species (30-40\%, including beech Fagus orientalis, alder Alnus glutinosa, and hornbeam Carpinus betulus, with rather similar proportions), and less than $5 \%$ pruned branches from fruit trees. All trees were cut from the neighboring forests located in Amol (Iran). These species were chosen by Khazar Co. to be used in their production program based on the availability in the region. The $\mathrm{pH}$ of the resin was 7. Continuous hot-press was used with a temperature range of $150-260{ }^{\circ} \mathrm{C}$ at different sections of the press. The duration of hot-press was $2 \mathrm{~min}$. Sanding was carried out on both sides of all panels, using sanding papers with 80, 100, and 150 grades. About $0.35-0.40 \mathrm{~mm}$ was sanded from each side of the panels. Particleboard panels were produced by Iran-Choob Company located in Ghazvin Industrial Complex, Ghazvin, Iran, the density of which was $730 \mathrm{~kg} \cdot \mathrm{m}^{-3}$. Wood chips consisted poplar (Populus nigra) (80-85\%) grown in the region and pruned branches from the neighboring fruit gardens (10-15\%). These species and raw materials were chosen by the producing factory based on the fact that poplar is considered a low density species, which makes it favorable for particleboard production. Moreover, the availability of poplar and pruned branches was of importance. 
Urea-formaldehyde resin contents were $17.5 \%$ and $10 \%$ based on the dry weight of wood chips for the surface and core layers, respectively. An addition of $1 \%$ ammonium chloride was used as a hardener. The $\mathrm{pH}$ of the resin was 7-8. A fixed hot-press was used with a temperature of $200{ }^{\circ} \mathrm{C}$. The specific pressure of the plates was $24 \mathrm{~kg} / \mathrm{cm}^{2}$ (with $200 \mathrm{kgf}$ as the total nominal pressure). The duration of the hot-press was $3 \mathrm{~min}$. Sanding was carried out on both sides of all panels, using sanding papers with 50, 100, and 120 grades. About $0.40-0.50 \mathrm{~mm}$ was sanded from each side of the panels. Based on the information provided by the seller, both composite panel types used urea-formaldehyde resin as a binder. The thickness of all panels was $16 \mathrm{~mm}$. From the center and two corners of each panel, two boards were cut with dimensions of $30 \mathrm{~cm} \times 30 \mathrm{~cm}$. From each board, three specimens were cut, the dimensions of which were $5 \mathrm{~cm} \times 5 \mathrm{~cm}$. In total, 27 specimens were prepared from either of the composite panels to be divided by three for each of the liquids (water, ethanol, and kerosene).

\subsection{Measurement of Penetration Time}

A drop of liquid was put on the surface center of each specimen (MDF or particleboard) by a $10 \mathrm{~mL}$ lab glass division dropper pipette. The time from the moment the drop first touched the specimen surface until it fully penetrated and disappeared was measured as the penetration time. The whole process was monitored by a $10 \times$ light magnifier.

\subsection{Measurement of Wetted Area}

Once the drop of liquid (water, ethanol, or kerosene) penetrated into the surface of the specimen and disappeared fully, the specimen was put on a stand to take a photo from the wetted spot at a constant distance between the surface and lens for all specimens. This confirmed that the magnification for all specimens was the same. Each and every photo was first converted to its negative form with black-and-white colour (Figure 1), and then analyzed by ImageJ software (version 1.53a, Wisconsin, WI, USA), to measure the wetted area. The area was then converted to square millimeter for comparison and reporting purposes.
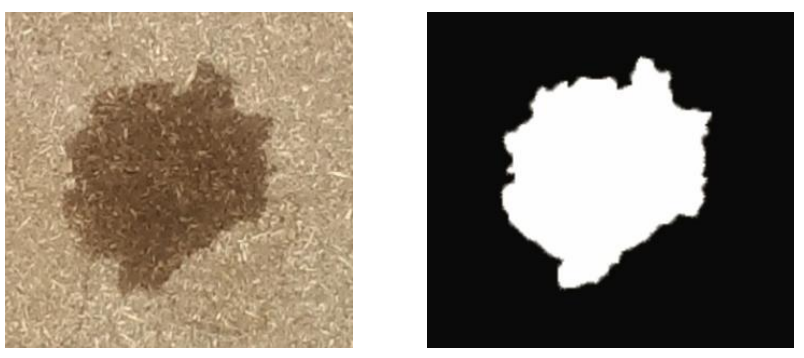

(a)
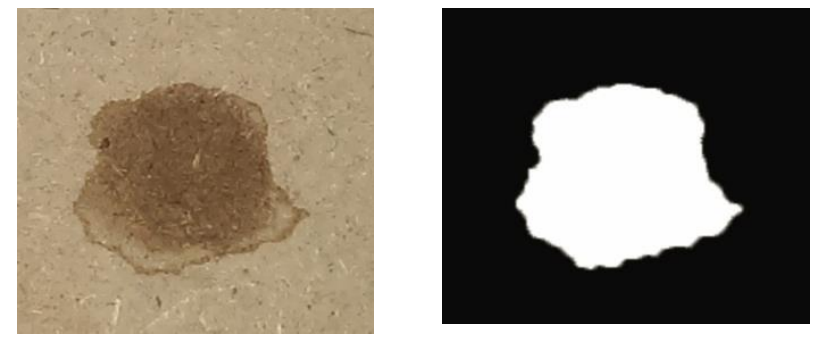

(b)

Figure 1. Photo at a constant distance from the wetted spot and the counterpart negative image of the same specimen in black-and-white in particleboard (a) and medium-density fiberboard (b) specimens. 


\subsection{Density Functional Theory (DFT)}

DFT simulations were carried out as instructed in the Open MX3.8 package [17]. The generalized gradient approximation, done with the aid of Perdew-Burke-Ernzerhof correction, was employed in order to get to the exchange-correlation function [18]. The DFT-D2 approach was used to include the long-range van der Waals interactions [19]. The plane wave cut-off energy was fixed at $60 \mathrm{Ry}$. The model of hemi-cellulose introduced by Kaith et al. [20] was considered in this study (Figure 2). All geometries were optimized until the maximum force on each atom was smaller than $0.001 \mathrm{eV} / \AA$.

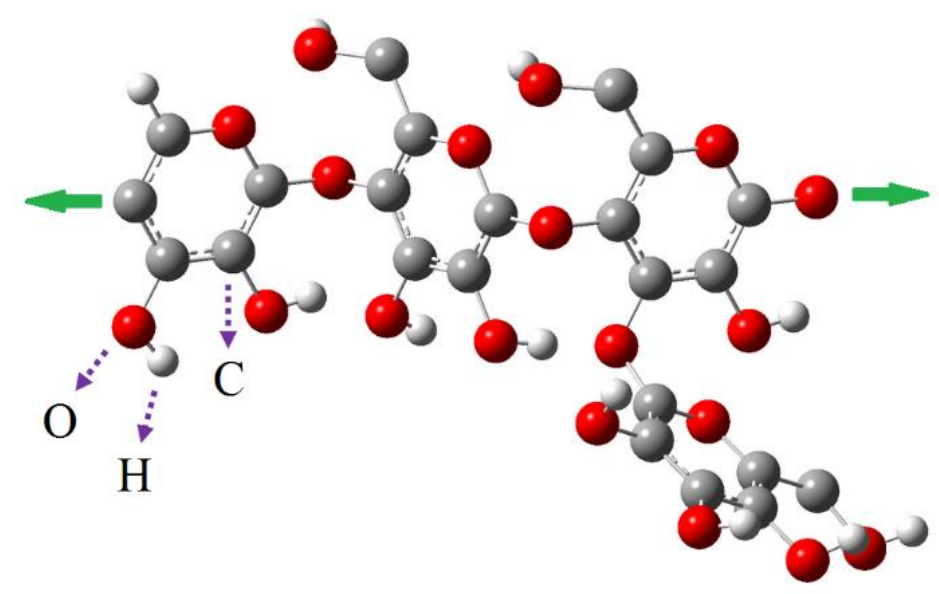

Figure 2. Atomic structure of hemi-cellulose.

In order to better interpret the potential interactions between each of the three liquids (water, ethanol, and kerosene), adsorption distances and adsorption energies of these three molecules on the hemicellulose surface were calculated by DFT. Each of the three molecules of water $\left(\mathrm{H}_{2} \mathrm{O}\right)$, ethanol $\left(\mathrm{C}_{2} \mathrm{H}_{5} \mathrm{OH}\right)$, or kerosene $\left(\mathrm{C}_{12} \mathrm{H}_{26}\right)$ were rotated on the hemicellulose surface to achieve the best configuration. Each process was initiated with the farthest distance, and then the distance became shortest until the optimal adsorption distance was achieved. Adsorption energy was calculated by Equation (1).

$$
E_{\text {ads }}=E_{\text {hemicellulose }+ \text { molecule }}-\left(E_{\text {hemicellulose }}+E_{\text {molecule }}\right)
$$

where $E_{\text {hemicellulose+molecule }}$ represents the total energy of hemicellulose including energy of the adsorbed molecule, and $E_{\text {hemicellulose }}$ and $E_{\text {molecule }}$ are the total energies of the hemicellulose surface and each of the adsorbed molecules (water, ethanol, and kerosene), respectively. The negative adsorption energy corresponded to the structure with the highest stability. Therefore, the highest stable construction was chosen as the ultimate configuration.

\subsection{Statistical Analysis}

The two composite panel types (MDF and particleboard) were produced and processed under different conditions, including the size of the materials (fibers and chips), resin content, surface sanding, tree species, and hot-press temperature. Therefore, a comparison between the two types of panels from a statistical point of view was not logical, because of the multiple sources of variance and factors involved. Therefore, analysis of variance (ANOVA) was separately carried out for the data and mean values of each composite type. However, both panel types are presented in joint graphs so that the readers would have a better outlook on the overall trends between the properties measured on the two types of composite panels. The calculations were carried out using SPSS /18 (2010). 


\section{Results}

\subsection{Penetration Time}

The results of the penetration of one drop of each of the three kinds of liquids demonstrated that the highest and lowest penetration times were found in MDF-water (2918.7 s \pm 507$)$ and MDF-alcohol (10.2 s \pm 3 ), respectively. Penetration of a water drop took significantly longer with water in comparison with the other two less polar liquids (alcohol and kerosene), in both MDF and particleboard specimens (Figure 3). No statistically significant difference was observed between the penetration of alcohol and kerosene, though fluctuations were observed between these liquids in the two composite panels.

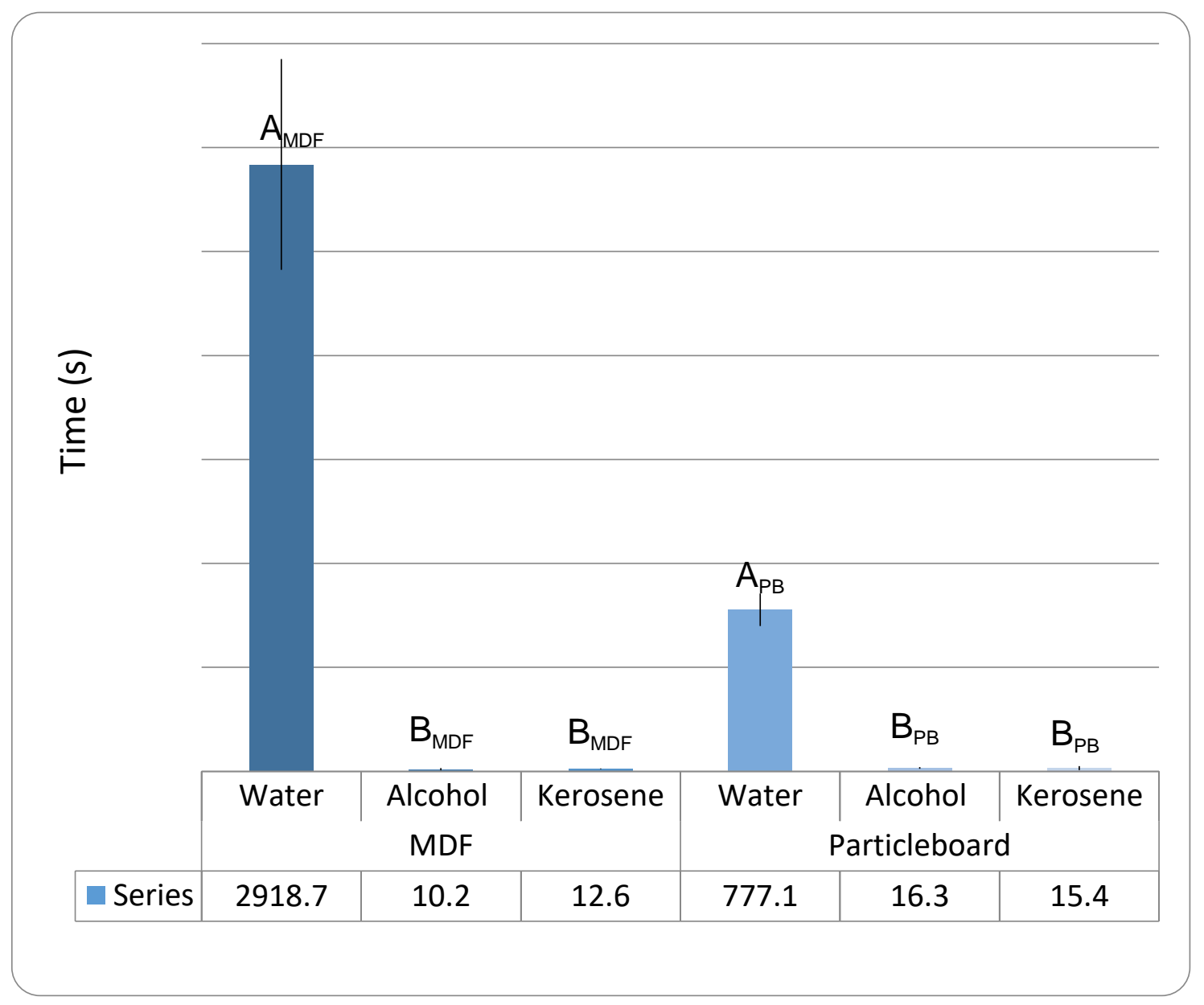

Figure 3. Penetration time for one drop of each of the three liquids (water, ethanol, and kerosene) to fully disappear from the surface of wood-based composite specimens (letters on each column represent Duncan's multiple range test, $\alpha=0.05$, separately carried out for either MDF or particleboard). MDF = medium-density fiberboard; $\mathrm{PB}=$ particleboard.

\subsection{Wetted Area}

The results of the measurement of the wetted area illustrated that water made a wider wetted area in comparison with alcohol and kerosene, in both MDF and particleboard composite panels. Unlike penetration time, a significant difference was observed between alcohol and kerosene in wetting the surface areas of both composite types (Figure 4). Wetted areas in particleboard were larger in comparison with their counterparts in MDF specimens for all three liquids. 


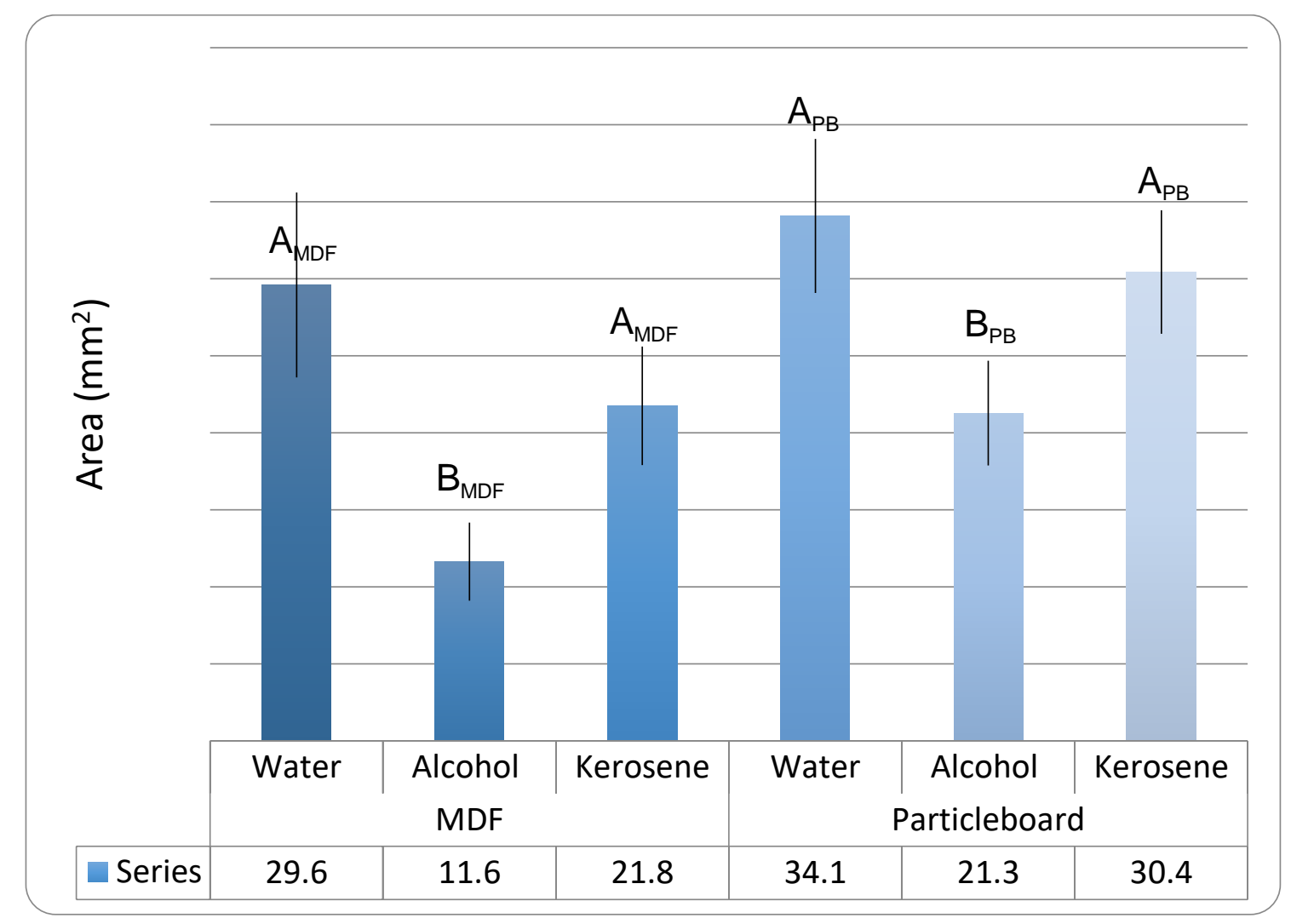

Figure 4. The wetted area in the wood-based composite specimens measured once the drop of liquid penetrated into the surface of composite specimen and fully disappeared (letters on each column represent Duncan's multiple range test, $\alpha=0.05$, separately carried out for either MDF or particleboard). MDF = medium-density fiberboard; $\mathrm{PB}=$ particleboard.

\subsection{Density Functional Theory (DFT)}

The adsorption energies between hemicellulose and the three liquids (water, ethanol, and kerosene), as well as the nearest adsorption distances, are listed in Table 1. The calculation of adsorption energy of the liquids on hemicellulose demonstrated that all three liquids were adsorbed on the hemicellulose surface. The nearest adsorption distance $(1.39 \AA)$ and the strongest adsorption energy $(-1.16 \mathrm{eV})$ were found in water molecules. As the smallest molecule between the three liquids, the model illustrated that water had the potential of penetrating into the hemicellulose complex and branched structure (Figure 5).

Table 1. Adsorption distance and adsorption energy for water, ethanol, and kerosene on hemicellulose.

\begin{tabular}{cccc}
\hline $\begin{array}{c}\text { Adsorption Distance } \\
\text { and Energy }\end{array}$ & $\begin{array}{c}\text { Water } \\
\mathbf{O H}_{\mathbf{w}} \ldots \mathbf{O}\end{array}$ & $\begin{array}{c}\text { Ethyl Alcohol } \\
\mathbf{O H}_{\mathbf{e}} \ldots \mathbf{O}\end{array}$ & $\begin{array}{c}\text { Kerosene } \\
\mathbf{C H} \ldots \mathbf{C}_{\mathbf{k}}\end{array}$ \\
\hline$d(\AA)$ & 1.39 & 1.40 & 1.67 \\
\hline$E_{\text {ads }}(\mathrm{eV})$ & -1.16 & -0.94 & -1.05 \\
\hline
\end{tabular}




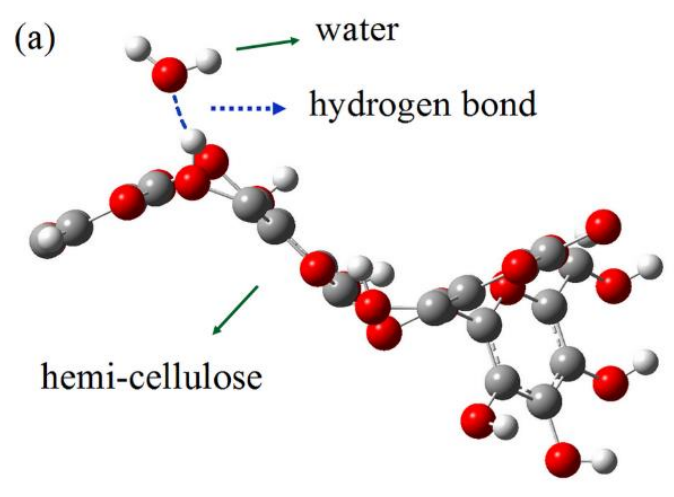

(b)
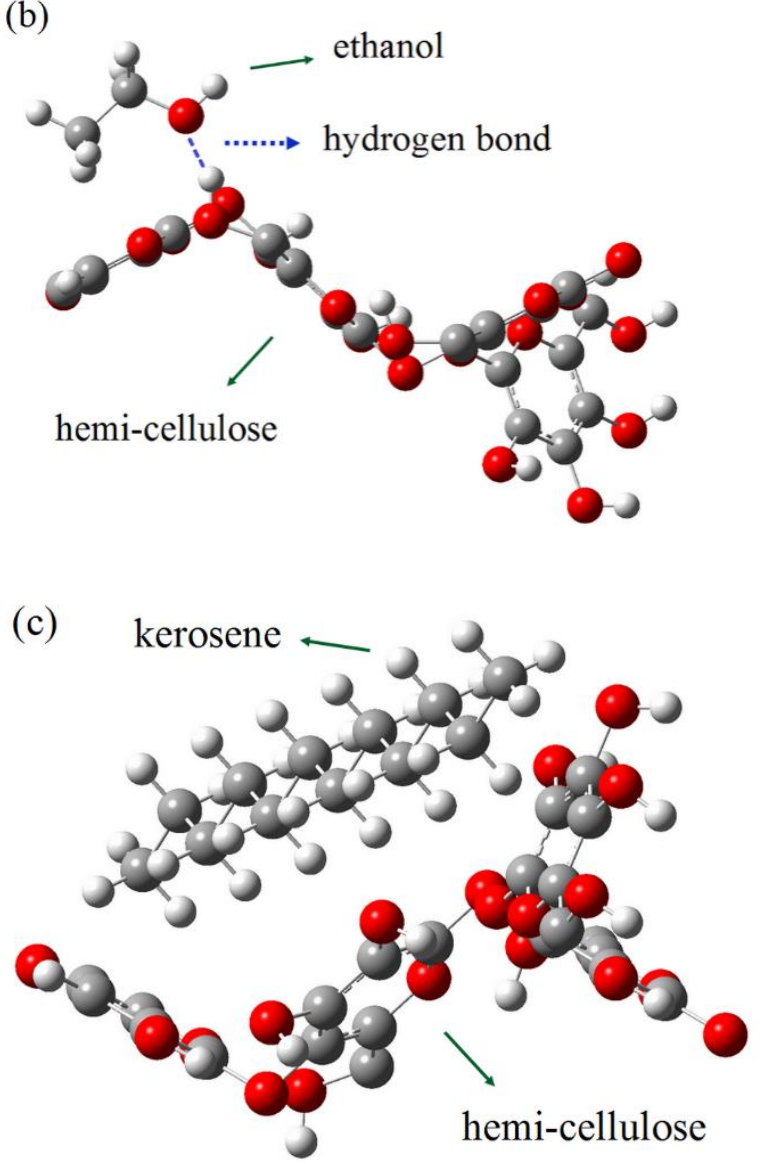

Figure 5. Schematic view of water $\left(\mathrm{H}_{2} \mathrm{O}\right)(\mathbf{a})$, ethanol $\left(\mathrm{C}_{2} \mathrm{H}_{5} \mathrm{OH}\right)(\mathbf{b})$, and kerosene $\left(\mathrm{C}_{12} \mathrm{H}_{26}\right)$ (c) molecules adsorbed on hemicellulose (the hydrogen bonds are shown with a dashed line).

\section{Discussion}

The highest adsorption energy, as well as the shortest adsorption distance, were both found between water molecules and the hemicellulose surface. The high adsorption energy translated to the formation of new bonds between water molecules and hemicellulose, eventually leading to a more stable bond between water molecules and hemicellulose. This partially accounted for slower movement and transfer of water molecules through the voids and spaces in both composite panels, resulting in a significant increase in penetration time for water in comparison with ethanol and kerosene (Figure 3). Though not statistically significant, Pearson correlations between the penetration time and wetted area calculated for the three liquids illustrated that correlation values for water were negative (in both MDF and particleboard specimens), while correlation values for ethanol and kerosene were positive. In this connection, a previous study on the liquid permeability of different 
medium-density fiberboard panels similarly reported that all MDF treatments indicated significantly lower water permeability in comparison with alcohol and kerosene permeability values [21]. The cited authors explained that water molecules primarily bonded with the hydroxyl groups of cellulose and hemicellulose in the cell wall [21-24]. These bonds delayed the movement and transfer of water molecules through the continuous voids and spaces in the composite specimens. However, the difference between the adsorption energies and distances of the three liquids on hemicellulose were not as great as the difference of the three liquids on cellulose, nor were they compatible with the difference between the penetration time or liquid permeability of the three liquids.

Further comparison between the adsorption energies of the three liquids (water, ethanol, and kerosene) on cellulose and hemicellulose revealed a significant difference between the energies of cellulose and hemicellulose, though the results of both the present and previous studies [21] clearly confirmed that water molecules have a higher degree of interaction with the hydroxyl groups of cell wall polymers (cellulose and hemicellulose) in comparison with ethanol and kerosene. That is, the adsorption energy of water molecules on cellulose was $55 \%$ and $44 \%$ higher in comparison with ethanol and kerosene, respectively [21]. However, the adsorption energy of water molecules on hemicellulose was only $19 \%$ and $9 \%$ higher in comparison with the counterpart energies of ethanol and kerosene on hemicellulose, respectively. This indicated that the significant differences between the penetration time and wetted area, as well as liquid permeability as studied previously [21], were mostly attributed to the difference of adsorption energy of the three liquids on cellulose rather than the low difference observed on hemicellulose. In this connection, further studies may evaluate the penetration time and wetted area in wood-based composite panels made with other types of resins than urea-formaldehyde resin to find out how different resins may affect the liquid penetration properties.

\section{Conclusions}

Penetration of water, a polar liquid with rather small molecules, into two woodbased composites was compared with two other less polar liquids, namely ethanol and kerosene. Full penetration of one drop of each of the three liquids into the composite texture was measured as the penetration time, and the area into which the drop of liquid expanded on the surface of the specimens was also measured and reported as the wetted area. Water demonstrated a significantly higher penetration time and wetted area. Density functional theory indicated a higher tendency of water molecules in forming more stable bonds on hemicellulose. Comparison of the three liquids on cellulose and hemicellulose demonstrated a higher impact of bonds between hydroxyl groups in water and cellulose in comparison with the bonds formed between water and hemicellulose. It was concluded that the higher penetration time and wetted area in water, in comparison with ethanol and kerosene, were mainly attributed to the formation of stronger and more stable bonds between the hydroxyl groups in water with cellulose.

Author Contributions: Methodology, H.R.T.; Validation, H.R.T., R.M., H.M., G.N., and A.N.P.; Investigation, H.R.T., M.G.A., and A.M.; Writing-Original Draft Preparation, H.R.T., R.M., and A.N.P.; Writing-Review and Editing, H.R.T., H.M., and A.N.P.; Visualization, H.R.T. and R.M.; Supervision, H.R.T. and A.N.P. All authors have read and agreed to the published version of the manuscript.

Funding: This research received no external funding.

Institutional Review Board Statement: Not applicable.

Informed Consent Statement: Not applicable.

Data Availability Statement: The data presented in this study are available on request from the corresponding author.

Acknowledgments: The first author appreciates constant scientific support of Jack Norton (Retired, Horticulture \& Forestry Science, Queensland Department of Agriculture and Fisheries, Australia), as well as Alexander von Humboldt Stiftung, Germany. 
Conflicts of Interest: The authors declare no conflict of interest.

\section{References}

1. Taghiyari, H.R.; Majidi, R.; Esmailpour, A.; Sarvari Samadi, Y.; Jahangiri, A.; Papadopoulos, A.N. Engineering composites made from wood and chicken feather bonded with UF resin fortified with wollastonite: A novel approach. Polymers 2020, $12,857$. [CrossRef] [PubMed]

2. Papadopoulos, A.N.; Gkaraveli, A. Dimensional stabilization and strength of particleboard by chemical modification with propionic anhydride. HolzalsRoh- Werkst. 2003, 61, 142-144. [CrossRef]

3. Goodge, K.; Frey, M. Biotin-conjugated cellulose nanofibers prepared via copper-catalyzed alkyne-azide cycloaddition (CuAAC) "click" chemistry. Nanomaterials 2020, 10, 1172. [CrossRef] [PubMed]

4. Taghiyari, H.R.; Esmailpour, A.; Majidi, R.; Hassani, V.; Abdolah Mirzaei, R.; Farajpour Bibalan, O.; Papadopoulos, A.N. The effect of silver and copper nanoparticles as resin fillers on less-studies properties of UF-based particleboards. Wood Mater. Sci. Eng. 2020. [CrossRef]

5. Platnieks, O.; Gaidukovs, S.; Barkane, A.; Sereda, A.; Gaidukova, G.; Grase, L.; Thakur, V.K.; Filipova, I.; Fridrihsone, V.; Skute, M.; et al. Bio-Based Poly(butylene succinate)/Microcrystalline Cellulose/Nanofibrillated Cellulose-Based Sustainable Polymer Composites: Thermo-Mechanical and Biodegradation Studies. Polymers 2020, 12, 1472. [CrossRef] [PubMed]

6. Shaoqiu, K.; Wang, Z.; Zhang, K.; Cheng, F.; Sun, J.; Wang, N.; Zhu, Y. Flexible conductive cellulose network-based composite hydrogel for multifunctional supercapacitors. Polymers 2020, 12, 1369.

7. Hassani, V.; Papadopoulos, A.N.; Schmidt, O.; Maleki, S.; Papadopoulos, A.N. Mechanical and Physical Properties of Oriented Strand Lumber (OSL): The Effect of Fortification Level of Nanowollastonite on UF Resin. Polymers 2019, 11, 1884. [CrossRef]

8. Taghiyari, H.R.; Esmailpour, A.; Majidi, R.; Morrell, J.J.; Mallaki, M.; Militz, H.; Papadopoulos, A.N. Potential Use of Wollastonite as a Filler in UF Resin Based Medium-Density Fiberboard (MDF). Polymers 2020, 12, 1435. [CrossRef]

9. Papadopoulos, A.N.; Taghiyari, H.R. Innovative wood surface treatments based on nanotechnology. Coatings 2019, 9, 866. [CrossRef]

10. Pizzi, A.; Papadopoulos, A.N.; Policardi, F. Wood composites and their polymer binders. Polymers 2020, 12, 1115. [CrossRef] [PubMed]

11. Wang, X.; Chen, X.; Xie, X.; Yuan, Z.; Cai, S.; Li, Y. Effect of phenol formaldehyde resin penetration on the quasi-static and dynamic mechanics of wood cell walls using nanoindentation. Nanomaterials 2019, 9, 1409. [CrossRef] [PubMed]

12. Antov, P.; Savov, V.; Mantanis, G.; Neykov, N. Medium-density fibreboards bonded with phenol-formaldehyde resin and calcium lignosulfonate as an eco-friendly additive. Wood Mat. Sci. Eng. 2020. [CrossRef]

13. Zorll, U. Neue Erkenntnisseüber die Bedeutung der Benetzungfür die AdhäsionbeiBeschichtungs- und Klebstoffen. Adhäsion 1978, 22, 320-325.

14. Hse, C.Y. Wettability of southern pine veneer by phenol formaldehyde wood adhesives. For. Prod. J. 1972, $22,51-56$.

15. Scheikl, M.; Dunky, M. Measurement of dynamic and static contact angles on wood for the determination of its surface tension and the penetration of liquids into the wood surface. Holzforschung 1998, 52, 89-94. [CrossRef]

16. Scheikl, M.; Dunky, M. Softwareunterstütztestatische und dynamischeKontaktwinkelmeßmethodenbei der Benetzung von Holz. HolzalsRoh- Werkst. 1996, 54, 113-117. [CrossRef]

17. Ozaki, T.; Kino, H.; Yu, J.; Han, M.J. User's Manual of OpenMX Version 3.8. 2018. Available online: http:/ / www.openmx-square. org/openmx_man3.8/openmx.html (accessed on 20 August 2018).

18. Perdew, J.P.; Burke, K.; Ernzerhof, M. Generalized Gradient Approximation Made Simple. Phys. Rev. Lett. 1996, 77, 3865. [CrossRef] [PubMed]

19. Grimme, S. Semiempirical GGA-type density functional constructed with a long-range dispersion correction. J. Comput. Chem. 2006, 27, 1787-1799. [CrossRef] [PubMed]

20. Kaith, B.S.; Mittal, H.; Jindal, R.; Maiti, M.; Kalia, S. Environment Benevolent Biodegradable Polymers: Synthesis, Biodegradability, and Applications. In Cellulose Fibers: Bio- and Nano-Polymer Composites; Kalia, S., Kaith, B., Kaur, I., Eds.; Springer: Berlin/Heidelberg, Germany, 2011.

21. Esmailpour, A.; Taghiyari, H.R.; Majidi, R.; Babaali, S.; Morrell, J.J.; Mohammadpanah, B. Effects of adsorption energy on air and liquid permeability of nanowollastonite-treated medium-density fiberboard. IEEE Trans. Instrum. Meas. 2020. [CrossRef]

22. Siau, J.F. Wood: Influence of Moisture on Physical Properties; Department of Wood Science and Forest Products Virginian Polytechnic Institute and State University: Blacksburg, VA, USA, 1995.

23. Siau, J.F. Transport Processes in Wood; Springer-Verlag: Berlin/Heidelberg, Germany; GmbH \& Co. KG: Berlin, Germany, 2011.

24. Skaar, C. Wood-Water Relations; Springer: Berlin/Heidelberg, Germany, 1988. 